\title{
Labile glycated haemoglobin and carbamylated haemoglobin are still critical points for $\mathrm{HbA}_{1 \mathrm{c}}$ measurement
}

\author{
Aurore Desmons ${ }^{* 1,2}$, Stéphane Jaisson ${ }^{1,2}$, Nathalie Leroy ${ }^{1}$, Philippe Gillery ${ }^{1,2}$, Emmanuelle Guillard ${ }^{1}$ \\ ${ }^{1}$ Laboratory of Pediatric Biology and Research, University Hospital of Reims, Reims, France \\ ${ }^{2}$ Laboratory of Medical Biochemistry and Medical Biology, Faculty of Medicine, University of Reims, Reims, France \\ *Corresponding author: adesmons@chu-reims.fr
}

\begin{abstract}
Introduction: Haemoglobin $\mathrm{A}_{1 \mathrm{C}}\left(\mathrm{HbA}_{1 \mathrm{c}}\right)$ is a key analyte for the monitoring of glycemic balance in diabetic patients and is used for diabetes diagnosis in many countries. The potential interference of carbamylated haemoglobin (CHb) and labile glycated haemoglobin ( $\left.\mathrm{LA}_{1 c}\right)$ on $\mathrm{HbA}_{1 \mathrm{c}}$ assays must remain a matter of vigilance. Such a situation has occurred in our laboratory with a kit replacement on the Bio-Rad Variant ${ }^{\mathrm{TM}}$ II testing system, a cation-exchange high performance liquid chromatography (HPLC) system. With this method, $\mathrm{LA}_{1 c}$ and $\mathrm{CHb}$ coeluted in a same peak which may have different consequences on $\mathrm{HbA}_{1 \mathrm{c}}$ values.
\end{abstract}

Materials and methods: The influence of increasing $\mathrm{LA}_{1 \mathrm{C}}$ and $\mathrm{CHb}$ values on $\mathrm{HbA}_{1 \mathrm{C}}$ results was studied with in vitro glycation and carbamylation of samples. Samples from patients with high and normal blood urea concentrations were assayed by HPLC and immunological assay.

Results: We observed that the degree of interference greatly varied depending on the nature of the interfering $\mathrm{Hb}$ fractions found under the socalled " $L A_{1 c}$ peak". Thus, we have decided to apply a decision tree using " $L A_{1 c}$ " thresholds depending on: (i) the retention time, (ii) the shape of the peak, (iii) other analytes, like urea. If the peak recognized as " $L A_{l c}$ " is mainly formed by $L A_{l c}$, we consider that there is no interference until $4 \%$. If the peak is mainly formed by $\mathrm{CHb}$, we consider an interference threshold equal to $2 \%$.

Conclusions: This situation reminds that $\mathrm{CHb}$ and $\mathrm{LA}_{1 \mathrm{c}}$ remain critical issues in chromatography-based $\mathrm{HbA}_{1 \mathrm{c}}$ assays and that adapted criteria must be set up for result interpretation.

Key words: carbamylated haemoglobin; labile glycated haemoglobin; $\mathrm{HbA}_{1 c^{\prime}}$; analytical interference

\section{Introduction}

Since its discovery as unusual haemoglobin fraction in patients with diabetes mellitus, $\mathrm{HbA}_{1 c^{\prime}}$ the major component of glycated haemoglobin, has proved to be a useful analyte for the monitoring of glycemic balance in diabetic patients, and for diabetes diagnosis in many countries (1-3). $\mathrm{HbA}_{1 \mathrm{c}}$ is also an important predictive marker of long term complications of diabetes $(4,5)$. $\mathrm{HbA}_{1 \mathrm{c}}$ assays can be performed using different analytical principles including separative methods such as high performance liquid chromatography (HPLC) and capillary electrophoresis, but also immunological and enzymatic methods.
The quality of assay methods for $\mathrm{HbA}_{1 \mathrm{c}}$ determination has greatly improved over the last decades, and most of analytical interferences have been controlled $(1,6)$. This is the case of carbamylated haemoglobin $(\mathrm{cHb})$, which results from the binding of urea-derived isocyanic acid and is increased in patients with chronic kidney disease. However, the potential interference of $\mathrm{cHb}$ on $\mathrm{HbA}_{1 \mathrm{c}}$ assays must remain of matter of vigilance $(7,8)$. Furthermore, interference may be caused by labile glycated haemoglobin ( $\mathrm{LA}_{1 \mathrm{c}}$ ), a labile and reversible fraction (Schiff base) formed at early stages of glyca- 
tion reaction, which directly depends on blood glucose concentration. Such a situation is reported here.

We have recently changed the kit for $\mathrm{HbA}_{1 \mathrm{c}}$ determination in our laboratory, by replacing the NU $\mathrm{Kit}^{\mathrm{TM}}$ by the Dual Kit Program ${ }^{\mathrm{TM}}$ on the Bio-Rad Variant $^{\mathrm{TM}}$ II testing system, based on cation-exchange HPLC. The analyser used for determination of $\mathrm{HbA}_{1 c}$ is the same, but the chromatography program (column, buffer gradient) and the peak integration software (column, buffer gradient) are different. The main advantage of the method with the new kit is the possibility to use the same method for $\mathrm{HbA}_{1 c^{\prime}}$, haemoglobin $\mathrm{A}_{2}$, and haemoglobin $\mathrm{F}$ measurements.

Most frequent interferences encountered with such HPLC-based methods have been evaluated (9). Whereas previous evaluations of this system did not report any interference studies (10), the instruction notes of the manufacturer mention a potential interference of $\mathrm{cHb}$ and $\mathrm{LA}_{1 \mathrm{c}}$ over $3 \%$. Using the Dual kit program ${ }^{\mathrm{TM}}, \mathrm{LA}_{1 \mathrm{c}}$ and $\mathrm{cHb}$ coeluted in a same peak called $\mathrm{LA}_{1 c^{\prime}}$ contrary to the former program NU Kit ${ }^{\mathrm{TM}}$ which allowed the separation in two peaks. As these two minor $\mathrm{Hb}$ fractions coelute in a single peak before $\mathrm{HbA}_{1 \mathrm{c}}$ peak, the consequences on $\mathrm{HbA}_{1 \mathrm{c}}$ value may differ according to the increased fractions (cHb or $\mathrm{LA}_{1 \mathrm{c}}$ ). Indeed, besides reporting the differences of chromatographic separation of $\mathrm{cHb}$ and $\mathrm{LA}_{1 \mathrm{c}}$ between the two kits, the aim of this study was to evidence that the influence of $\mathrm{cHb}$ or $\mathrm{LA}_{1 \mathrm{c}}$ on $\mathrm{HbA}_{1 c}$ measurements remains a critical issue and to propose a decision tree for managing these interferences in routine practice with this method.

\section{Materials and methods}

\section{Subjects}

This study was performed from September to October 2016 in the Laboratory of Pediatric Biology and Research at the University Hospital of Reims.

Blood samples used for this study were received in the routine workload of the laboratory for $\mathrm{HbA}_{1 \mathrm{c}}$ assay as part of the follow-up of 19 patients. The interference noticed with the new kit was evi- denced during regularly ordered $\mathrm{HbA}_{1 \mathrm{c}}$ assays. No other biological investigation than $\mathrm{HbA}_{1 \mathrm{c}}$ assay was performed, and additional experiments exclusively aimed at providing an interpretable $\mathrm{HbA}_{1 c}$ result in patients.

Among these samples, those from patients with physiological $(<7.15 \mathrm{mmol} / \mathrm{L})$ or increased blood urea ( $>.15 \mathrm{mmol} / \mathrm{L})$ were assayed by two methods (HPLC and immunological assay).

\section{Blood samples}

Blood samples sent to the laboratory for $\mathrm{HbA}_{1 \mathrm{c}}$ assays using Variant II $^{\mathrm{TM}}$ analyser were collected in 5 $\mathrm{mL}$ ethylenediamine tetra-acetic acid dipotassium salt ( $\mathrm{K}_{2}$ EDTA)-containing tubes (ref. 367962, Becton Dickinson, Franklin Lakes, New Jersey, USA) and stored at $+4^{\circ} \mathrm{C}$ before analysis. The minimum required volume, for the primary tube, was $1 \mathrm{~mL}$. For DCA Vantage ${ }^{\circledR}$ analyser, $1 \mu \mathrm{L}$ of capillary blood, obtained by finger skin puncture or venous punction (acceptable anticoagulants being $\mathrm{K}_{2}$ EDTA, heparin, fluoride/oxalate and citrate) was required. Capillary holders, which contain glass capillary, are provided by Siemens in DCA ${ }^{\mathrm{TM}}$ Systems Hemoglobin $A_{1 c}$ Reagent Kit.

For urea measurement, blood samples were collected on lithium heparin-containing tubes (ref. 367884, Becton Dickinson, Franklin Lakes, New Jersey, USA). The minimum required volume was 1 $\mathrm{mL}$ for primary tubes.

\section{Methods}

Blood urea was assayed on Cobas ${ }^{\circledR} 8000$ modular analyser series on c701 and c502 modules (Roche Diagnostics, Mannheim, Germany). Determination of blood urea was based on kinetic test using urease and glutamate dehydrogenase.

Variant II Hemoglobin Testing System ${ }^{\mathrm{TM}}$ (Bio-Rad, Marnes-la-Coquette, France) is a completely automated system for $\mathrm{HbA}_{1 \mathrm{c}}$ measurement based on cation-exchange HPLC. Samples are automatically mixed, diluted on the station and injected into the column. Haemoglobins are separated based on their ionic interactions with the stationary phase. The mobile phase is composed of phosphate buff- 
er; the chromatographic station delivers a gradient of increasing ionic strength to the cartridge. The separated haemoglobins pass through the flow cell of the filter photometer, and changes in the absorbance are measured at $415 \mathrm{~nm}$, and at $690 \mathrm{~nm}$ for background correction.

Intra-assay coefficients of variation (CVs), calculated from patient samples, were $0.4 \%, 0.7 \%$ and $0.4 \%$ for $\mathrm{HbA}_{1 \mathrm{c}}$ values (expressed in percentages) of $5.4 \%, 7.3 \%$ and $12.8 \%$, respectively. Between-assay CVs, calculated from quality control results, Bio-Rad Lyphocheck Diabetes Controls (Bio-Rad Laboratories Inc, Hercules, CA, USA), were 1.1\% and $1.3 \%$ for $\mathrm{HbA}_{1 \mathrm{c}}$ values of $5.7 \%$ and $9.4 \%$, respectively. Measurement uncertainties represented $0.27 \%$ and $0.38 \%$ for $\mathrm{HbA}_{1 \mathrm{c}}$ values of $5.6 \%$ and 9.4\%, respectively. Bio-Rad Lyphocheck Diabetes Controls were used as quality control (QC) materials and assayed at the beginning and at the end of each assay series. Between-assay CVs were $1.0 \%$ and $1.2 \%$ for expected values at $5.2 \%$ and $10.1 \%$ of $\mathrm{HbA}_{1 \mathrm{c}}$ respectively.

DCA Vantage ${ }^{\circledR}$ (Siemens Healthcare, St Denis, France) system relies on an immunological assay. The concentrations of $\mathrm{HbA}_{1 \mathrm{c}}$ and total haemoglobin are both measured in parallel and the ratio reported as percent. For total haemoglobin measurement, haemoglobin is oxidized in methaemoglobin, then methaemoglobin complexes with thiocyanate to form thiocyan-methaemoglobin, the absorbance of coloured species being measured at $531 \mathrm{~nm}$. The measurement of $\mathrm{HbA}_{1 \mathrm{c}}$ is based on a latex agglutination inhibition method using monoclonal antibodies. An agglutinator, containing immunoreactive portion of $\mathrm{HbA}_{1 \mathrm{c}^{\prime}}$ causes the agglutination of latex particles coated with $\mathrm{HbA}_{1 \mathrm{c}}$ monoclonal antibody. The agglutination reaction increases scattering of light measured as an increase of absorbance at $531 \mathrm{~nm}$. $\mathrm{HbA}_{1 \mathrm{c}}$ in patient blood sample inhibits the interaction between the agglutinator and latex particles and decreases scattering of light, measured as a decrease in absorbance at $531 \mathrm{~nm}$.

Intra-assay CVs, calculated from patient samples, were $1.5 \%$ and $2.7 \%$ for $\mathrm{HbA}_{1 \mathrm{c}}$ values (expressed in percentages) of $5.2 \%$ and $7.7 \%$, respectively. Be- tween-assay CVs, calculated from quality control results (Bio-Rad Lyphocheck Diabetes Controls) were $1.8 \%$ and $1.7 \%$ for $\mathrm{HbA}_{1 \mathrm{c}}$ values of $5.6 \%$ and $10.2 \%$, respectively. Measurement uncertainties represented $0.61 \%$ and $0.67 \%$ for $\mathrm{HbA}_{1 \mathrm{c}}$ values of $5.6 \%$ and $10.2 \%$, respectively. Bio-Rad Lyphocheck Diabetes Controls were used as QC materials and assayed at the beginning and at the end of each assay series. Between-assay CVs were $1.8 \%$ and $2.3 \%$ for expected values at $5.6 \%$ and $9.9 \%$ of $\mathrm{HbA}_{1 c^{\prime}}$, respectively.

In the Dual kit program ${ }^{\mathrm{TM}}, \mathrm{LA}_{1 \mathrm{c}}$ and $\mathrm{CHb}$ coeluted in a same peak called $L A_{1 c^{\prime}}$ contrary to the former program NU Kit ${ }^{\mathrm{TM}}$ which allowed the separation in two peaks. This peak, which elutes just before $\mathrm{HbA}_{1 \mathrm{c}}$ peak, may represent a potential interference on $\mathrm{HbA}_{1 \mathrm{c}}$ quantification.

\section{Procedures for in vitro carbamylation and glycation}

Whole blood samples were selected according the following criteria: haematocrit value in reference ranges, low $L_{1 c}$ value $(<1.5 \%)$, and two $\mathrm{HbA}_{1 c}$ levels (within reference range and over 7\%).

Two $\mathrm{mL}$ of whole blood were centrifuged $\left(4^{\circ} \mathrm{C}, 8\right.$ minutes, $3000 \mathrm{~g})$, plasma removed, and three washes $\left(4{ }^{\circ} \mathrm{C}, 8\right.$ minutes, $\left.3000 \times \mathrm{g}\right)$ of red blood cells (RBC) performed with $\mathrm{NaCl} 0.15 \mathrm{M}$ (saline). $200 \mu \mathrm{L}$ of KCNO (Sigma-Aldrich, St Louis, Missouri, USA), prepared at different concentrations: $0.125 \mathrm{mM}, 0.250 \mathrm{mM}, 0.375 \mathrm{mM}, 0.500 \mathrm{mM}, 0.750$ $\mathrm{mM}$, were added and incubated for 3 hours at 37 ${ }^{\circ} \mathrm{C}$. A control series was performed by incubating $200 \mu \mathrm{L} \mathrm{KCl}$ instead of KCNO. After centrifugation (room temperature (RT), 30 seconds, 20,000 x g), supernatant was removed and 2 washes were performed (RT, 30 seconds, 20,000 x g) with saline. $200 \mu \mathrm{L}$ of saline were added, and $\mathrm{HbA}_{1 \mathrm{c}}$ assayed on Variant ${ }^{\mathrm{IM}}{ }^{\mathrm{TM}}$ system.

\section{Procedure for in vitro glycation}

Two $\mathrm{mL}$ of whole blood were centrifuged $\left(4^{\circ} \mathrm{C}, 8\right.$ minutes, $3000 \times \mathrm{g}$ ), plasma removed, and three washes of RBC performed with saline. $200 \mu \mathrm{L}$ of $0.250 \mathrm{mM}$ glucose (alpha-D-glucose anhydrous 96\%; Sigma-Aldrich, St Louis, Missouri, USA) solution in saline were added to RBC pellet and incu- 
bated for $0,15,17,22,27,30,45$ minutes at $37^{\circ} \mathrm{C}$. After centrifugation (RT, 30 seconds, 20,000 x g), supernatant was removed and replaced by $200 \mu \mathrm{L}$ of $5 \mathrm{mM}$ glucose, and $\mathrm{HbA}_{1 \mathrm{c}}$ assayed on Variant $\mathrm{II}^{\mathrm{TM}}$ system.

\section{Statistical analysis}

In vitro glycation or carbamylation experiments were analysed in triplicate. Results were expressed as means.

Relative and absolute biases were obtained with following formulas:

$$
\text { Relative bias }=\left(\frac{x-y}{y}\right) \times 100
$$

$$
\text { Relative bias }=x-y
$$

where $x=\mathrm{HbA}_{1 c}$ measured with Variant II ${ }^{\mathrm{TM}}$ analyser and $\mathrm{y}=\mathrm{HbA}_{1 \mathrm{c}}$ measured with DCA Vantage ${ }^{\circledR}$ analyser.

Uncertainty measurement (U) was calculated using the following formulas:

$$
\begin{gathered}
U=2 \times u(C) \\
u(C)=\sqrt{u^{2}(I Q C)+u^{2}(E Q E)} \\
u(I Q C)=\frac{C V \times \mathrm{m}}{100} \\
u(E Q E)=\sqrt{\left(\frac{|\bar{E}|}{\sqrt{3}}\right)^{2}+\hat{\sigma}_{\mathrm{E}}^{2}} \\
\hat{\sigma}_{\mathrm{E}}^{2}=\frac{\sum_{\mathrm{i}}\left(E_{i}-\bar{E}\right)^{2}}{\mathrm{n}-1} \\
\bar{E}=\frac{\sum_{\mathrm{i}}\left(x_{\text {lab }}-x_{\text {ref }}\right) \mathrm{i}}{\mathrm{n}} \\
\left.E_{i}=\operatorname{silab}_{\text {lab }}-x_{\text {ref }}\right)
\end{gathered}
$$

where IQC represents internal quality control, EQE external quality control, CV coefficient of variation, $\mathrm{m}$ represents the mean; $\mathrm{x}_{\mathrm{lab}}$ laboratory result; $\mathrm{x}_{\text {ref }}$ reference value.

The measurement uncertainty of the Variant $\mathrm{II}^{\mathrm{TM}}$ system, calculated with the above formulas and equal to $0.3 \%$, was used as a threshold to determine a significant difference between $\mathrm{HbA}_{1 c}$ results.

\section{Results}

First, we studied the influence of increasing $L A_{1 c}$ values on $\mathrm{HbA}_{1 \mathrm{c}}$ results, and showed that the increase of $\mathrm{LA}_{1 c}$ peak led to a decrease of $\mathrm{HbA}_{1 c}$ values (Table 1), the threshold of $0.3 \%$ being used as acceptance criterion to determine a significant difference between $\mathrm{HbA}_{1 c}$ results. Thus, a significant interference was noticed when $L A_{1 c}$ exceeded $4 \%$. Second, we studied the influence of $\mathrm{cHb}$ interference and found a significant interfering effect when $\mathrm{cHb}$ exceeded $2 \%$ (Table 2 ).

Thus, both $\mathrm{LA}_{1 \mathrm{c}}$ and $\mathrm{cHb}$ interfered with $\mathrm{HbA}_{1 \mathrm{c}}$ determination, but it was noteworthy that the influence of the peak recognized as $\mathrm{LA}_{1 \mathrm{c}}$ on chromatogram depended on the nature of the interference. When the interference was caused by $\mathrm{cHb}, \mathrm{HbA}_{1 c}$ decrease was more prominent than when caused by $L A_{1 c}$. For example, for an initial level of $\mathrm{HbA}_{1 \mathrm{c}}$ equal to $5.2 \%(33 \mathrm{mmol} / \mathrm{mol})$ with a $\mathrm{LA}_{1 c}$ peak at $1.2 \%$, the increase of $L A_{1 c}$ peak to $3.4 \%$ due to glycation ( $\mathrm{LA}_{1 \mathrm{c}}$ increase) led to a decrease of $\mathrm{HbA}_{1 \mathrm{c}}$ value to $4.9 \%$ (30 mmol $/ \mathrm{mol})$, whereas it was $4.4 \%$ (25 $\mathrm{mmol} / \mathrm{mol}$ ) when the interference was due to carbamylation (cHb). Similar results were found using a sample with initial $\mathrm{HbA}_{1 c}$ value of $8.1 \%(65 \mathrm{mmol} /$ mol): a decrease of $\mathrm{HbA}_{1 c}$ to a value at $7.7 \%(61$ $\mathrm{mmol} / \mathrm{mol}$ ) was observed for a $\mathrm{cHb}$ value of $2.2 \%$ whereas it was observed only at $4.6 \%$ of $\mathrm{LA}_{1 c}$ (Tables 1 and 2). The impact of $\mathrm{cHb}$ and $\mathrm{LA}_{1 \mathrm{c}}$ on the $\mathrm{HbA}_{1 \mathrm{c}}$ measurements (Tables 1 and 2) was also highlighted using a graphical presentation (Figure 1).

Interestingly, we observed that chromatograms differed regarding retention time (higher for $\mathrm{CHb}$ than for $L A_{1 c}$ ) and peak shape depending on the origin of the interference $\left(\mathrm{LA}_{1 c}\right.$ or $\left.\mathrm{cHb}\right)$, even though the peak was only recognized as $L A_{1 c}$ by the software (Figure 2). 
TABLE 1. Interference of labile glycated hemoglobin $\left(\mathrm{LA}_{1 c}\right)$ on $\mathrm{HbA}_{1 c}$ measurements by Variant II equipped with Dual kit program ${ }^{\mathrm{TM}}$

\begin{tabular}{|c|c|c|c|c|c|c|c|}
\hline Incubation time (min) with $0.25 \mathrm{~mol} / \mathrm{L}$ glucose & 0 & 15 & 17 & 22 & 27 & 30 & 45 \\
\hline $\mathrm{HbA}_{1 c}{ }^{\dagger}, \mathrm{mmol} / \mathrm{mol}$ & 33 & 31 & 30 & 30 & 28 & 27 & 25 \\
\hline $\mathrm{HbA}_{1 c}^{\dagger}, \%$ & 5.2 & 5.0 & 4.9 & 4.9 & $4.7^{*}$ & $4.6^{*}$ & $4.4^{*}$ \\
\hline Peak recognized as $« \mathrm{LA}_{1 \mathrm{c}}{ }^{\dagger}, \%$ & 1.2 & 3.1 & 3.4 & 4.0 & 4.5 & 4.8 & 6.3 \\
\hline $\mathrm{HbA}_{1 \mathrm{c}}{ }^{\dagger}, \mathrm{mmol} / \mathrm{mol}$ & 65 & 64 & 64 & 62 & 61 & 60 & 56 \\
\hline $\mathrm{HbA}_{1 c}^{\dagger}, \%$ & 8.1 & 8.0 & 8.0 & 7.8 & $7.7^{*}$ & $7.6^{*}$ & $7.3^{*}$ \\
\hline Peak recognized as «LA $\left.A_{1 c}\right\rangle^{\dagger}, \%$ & 1.3 & 3.1 & 3.4 & 4.0 & 4.6 & 4.8 & 6.2 \\
\hline
\end{tabular}

${ }^{*}$ Differences higher than $0.3 \%$ compared to initial value of $\mathrm{HbA}_{1 \mathrm{c}} \cdot{ }^{\mathrm{t}}$ mean of triplicate measurements.

TABLE 2. Interference of carbamylated hemoglobin ( $\mathrm{cHb}$ ) on $\mathrm{HbA}_{1 \mathrm{c}}$ measurements by Variant Il equipped with Dual kit program ${ }^{\mathrm{TM}}$

\begin{tabular}{|c|c|c|c|c|c|c|}
\hline 3h-incubation with KCNO (mmol/L) & 0.000 & 0.125 & 0.250 & 0.375 & 0.500 & 0.750 \\
\hline $\mathrm{HbA}_{1 \mathrm{c}}{ }^{\dagger}, \mathrm{mmol} / \mathrm{mol}$ & 33 & 32 & 31 & 30 & 28 & 25 \\
\hline $\mathrm{HbA}_{1 \mathrm{c}}{ }^{\dagger}, \%$ & 5.2 & 5.1 & 5.0 & 4.9 & $4.7^{*}$ & $4.4^{*}$ \\
\hline Peak recognized as «LA ${ }_{1 c} \|^{\dagger}, \%$ & 1.2 & 1.4 & 1.7 & 2.1 & 2.5 & 3.4 \\
\hline $\mathrm{HbA}_{1 \mathrm{c}}{ }^{\dagger}, \mathrm{mmol} / \mathrm{mol}$ & 65 & 64 & 61 & 59 & 55 & 50 \\
\hline $\mathrm{HbA}_{1 \mathrm{c}}{ }^{\dagger}, \%$ & 8.1 & 8.0 & $7.7^{*}$ & $7.5^{*}$ & $7.2^{*}$ & $6.7^{*}$ \\
\hline Peak recognized as «LA $\left.{ }_{1 c}\right\rangle^{\dagger}, \%$ & 1.3 & 1.6 & 2.2 & 2.8 & 3.5 & 4.8 \\
\hline
\end{tabular}

${ }^{*}$ Differences higher than $0.3 \%$ compared to initial value of $\mathrm{HbA}_{1 \mathrm{c}} \cdot{ }^{\dagger}$ Mean of triplicate measurements.

To go further into the investigation of the impact of $\mathrm{cHb}$ on $\mathrm{HbA}_{1 \mathrm{c}}$ measurements, we performed a comparison between $\mathrm{HbA}_{1 \mathrm{c}}$ values obtained with the Dual Kit Program ${ }^{\mathrm{TM}}$ (Bio-Rad) device and with the immunoassay-based DCA Vantage ${ }^{\circledR}$ (Siemens Healthcare) which is not influenced by $\mathrm{CHb}$ (11). Because uraemia is the main cause of increased carbamylation (12), and consequently of cHb formation, samples from 7 patients with increased blood urea (> $7.15 \mathrm{mmol} / \mathrm{L})$ were assayed by both methods. Negative absolute and relative biases were evidenced in all samples with increased blood urea. Mean relative and absolute biases calculated were $-8.2 \%$ and $-5 \mathrm{mmol} / \mathrm{L}$ (- $0.5 \%)$, respectively (Table 3). By contrast, a similar comparison performed in samples from patients without hyperuraemia (urea $<7.15 \mathrm{mmol} / \mathrm{L}$ ) showed mean relative and absolute biases equal to $+0.9 \%$ and +1.1 $\mathrm{mmol} / \mathrm{mol}(+0.1 \%)$ respectively (Table 4$)$.

\section{Discussion}

Because $\mathrm{HbA}_{1 \mathrm{c}}$ is widely used for the diagnosis of diabetes and the monitoring of diabetic patients, its quantification must be performed using robust and high quality methods (2). HPLC is commonly used for assaying $\mathrm{HbA}_{1 c^{\prime}}$ and the potential interferences, like those generated by $\mathrm{LA}_{1 \mathrm{c}}$ and $\mathrm{cHb}$, have generally been well described. However, these additional $\mathrm{Hb}$ fractions may still cause unexpected interferences $(7,8,13)$. A previous study investigating the influence of $\mathrm{cHb}$ to $\mathrm{HbA}_{1 \mathrm{c}}$ measurements by Bio-Rad Variant $\mathrm{II}^{\mathrm{TM}}$ analyser equipped with $\mathrm{NU}$ $\mathrm{Kit}^{\mathrm{TM}}$ did not evidence such an impact of $\mathrm{cHb}$ but recommended an interpretation with caution when $\mathrm{CHb}$ was increased (14).

Using the Dual kit program ${ }^{\mathrm{TM}}, \mathrm{LA}_{1 \mathrm{c}}$ and $\mathrm{CHb}$ coeluted in a same peak called $L A_{1 c^{\prime}}$ contrary to the former program NU Kit ${ }^{\mathrm{TM}}$ which allowed the separation in two peaks. This peak which elutes just before $\mathrm{HbA}_{1 \mathrm{c}}$ peak could represent a potential interference on $\mathrm{HbA}_{1 c}$ quantification. 
A

Interference of $\mathrm{LA}_{1 \mathrm{c}}$
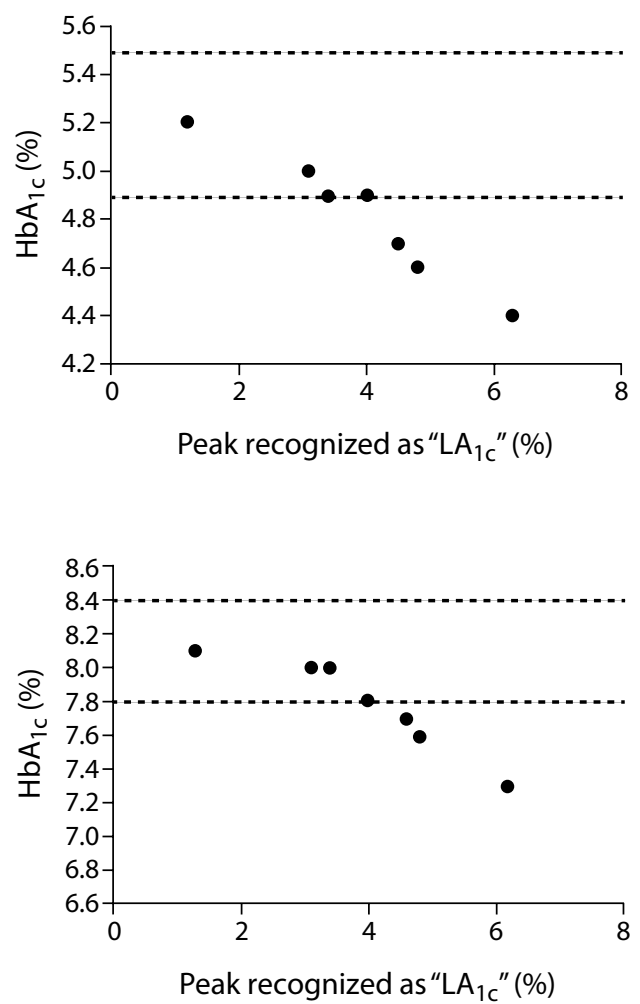

B

Interference of $\mathrm{cHb}$
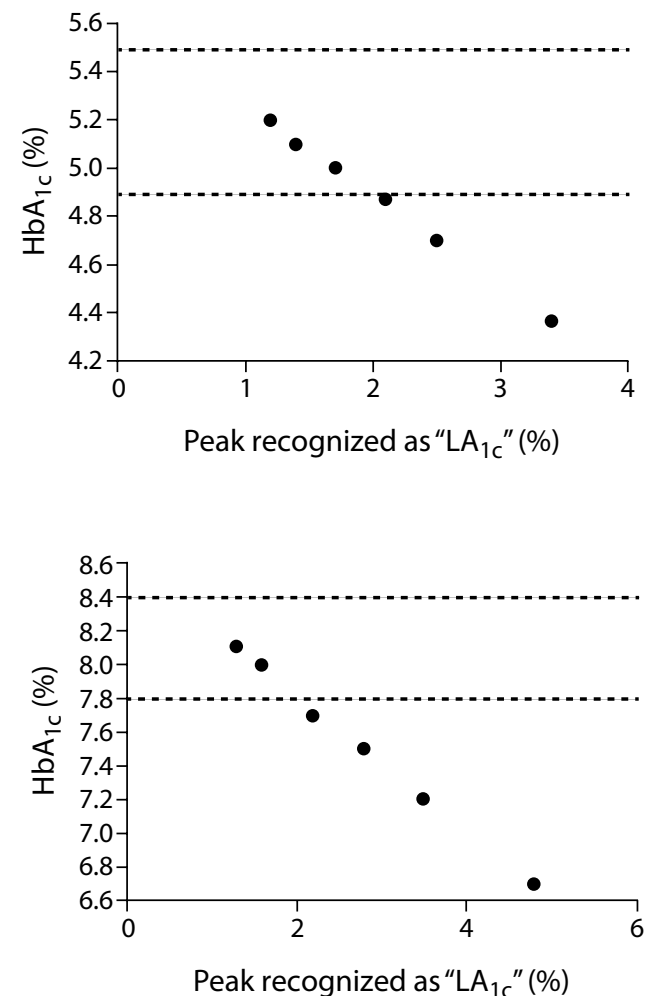

FiguRE 1. Interference of $\mathrm{LA}_{1 c}(\mathrm{~A})$ and $\mathrm{CHb}(\mathrm{B})$ on $\mathrm{HbA}_{1 c}$ measurement by Variant II equipped with Dual Kit Program ${ }^{\mathrm{TM}}$.

For each interference, two samples with different levels of $\mathrm{HbA}_{1 \mathrm{c}}(5.2 \%$ and $8.1 \%)$ have been tested. The dashed lines represent the values above which the differences have been considered significant (initial $\mathrm{HbA}_{1 \mathrm{c}}$ values $\pm 0.3 \%$, which corresponds to the measurement uncertainty of the method).
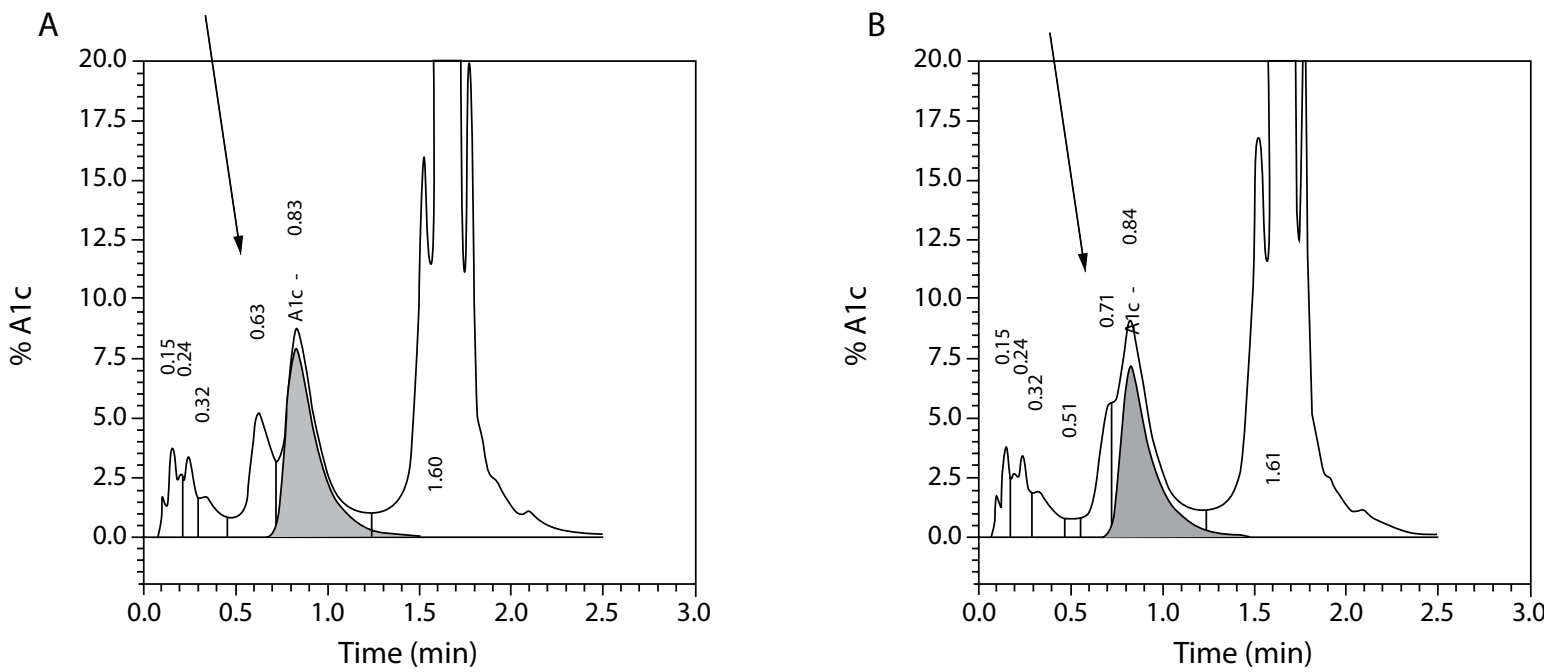

Figure 2. Chromatograms obtained in case of an increase of the "LA $A_{1 c}$ peak" due to $A$ : $L A_{1 c}$ (elution time: $0.63 \mathrm{~min}$ ) or $B$ : $c H b$ (elution time: $0.71 \mathrm{~min})$. 
TABLE 3. Comparison of $\mathrm{HbA}_{1 \mathrm{c}}$ results obtained using Variant II Dual kit program ${ }^{\mathrm{TM}}$ and DCA Vantage ${ }^{\circledR}$ in patients with hyperuraemia

\begin{tabular}{|c|c|c|c|c|c|}
\hline & $\begin{array}{c}\mathrm{HbA}_{1 \mathrm{c}^{\prime}} \\
\mathrm{mmol} / \mathrm{mol}^{(\%) *}\end{array}$ & 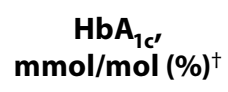 & $\begin{array}{c}\text { Relative bias, } \\
\%\end{array}$ & $\begin{array}{c}\text { Absolute bias, } \\
\mathrm{mol} / \mathrm{mol}(\%)\end{array}$ & $\begin{array}{c}\text { Blood urea, } \\
\mathrm{mmol} / \mathrm{L}\end{array}$ \\
\hline Patient 1 & $31(5.0)$ & $40(5.8)$ & -13.7 & $-9(-0.8)$ & 27.8 \\
\hline Patient 2 & $53(7.0)$ & $58(7.5)$ & -6.6 & $-5(-0.5)$ & 25.0 \\
\hline Patient 3 & $38(5.6)$ & $42(6.0)$ & -6.6 & $-4(-0.4)$ & 15.3 \\
\hline Patient 4 & $55(7.2)$ & $58(7.5)$ & -4.0 & $-3(-0.3)$ & 29.0 \\
\hline Patient 5 & $27(4.6)$ & $33(5.2)$ & -11.5 & $-5(-0.6)$ & 9.0 \\
\hline Patient 6 & $30(4.9)$ & $34(5.3)$ & -7.6 & $-4(-0.4)$ & 30.9 \\
\hline Patient 7 & $44(6.2)$ & $48(6.7)$ & -7.5 & $-4(-0.5)$ & 24.0 \\
\hline Mean biases & & & -8.2 & $-5(-0.5)$ & \\
\hline
\end{tabular}

${ }^{*}$ Determined using Variant II. ${ }^{\dagger}$ Determined using DCA Vantage.

TABLE 4. Comparison of $\mathrm{HbA}_{1 C}$ results obtained using Variant II Dual kit program ${ }^{\mathrm{TM}}$ and DCA Vantage ${ }^{\circledR}$ in non-uraemic patients

\begin{tabular}{|c|c|c|c|c|c|}
\hline & $\begin{array}{c}\mathrm{HbA}_{1 \mathrm{c}^{\prime}} \\
\mathrm{mmol} / \mathrm{mol}^{(\%) *}\end{array}$ & $\begin{array}{c}\mathrm{HbA}_{1 \mathrm{c}^{\prime}} \\
\left.\mathrm{mmol} / \mathrm{mol}^{(\%)}\right)^{\dagger}\end{array}$ & Relative bias, \% & $\begin{array}{l}\text { Absolute bias, } \\
\mathrm{mol} / \mathrm{mol}(\%)\end{array}$ & $\begin{array}{c}\text { Blood urea, } \\
\mathrm{mmol} / \mathrm{L}\end{array}$ \\
\hline Patient 1 & $37(5.5)$ & $37(5.5)$ & 0.0 & $0(0.0)$ & 4.2 \\
\hline Patient 2 & $88(10.2)$ & $79(9.4)$ & 8.5 & $9(0.8)$ & 7.0 \\
\hline Patient 3 & $50(6.7)$ & $46(6.4)$ & 4.7 & $4(0.3)$ & 7.0 \\
\hline Patient 4 & $34(5.3)$ & $34(5.3)$ & 0.0 & $0(0.0)$ & 7.0 \\
\hline Patient 5 & $58(7.5)$ & $57(7.4)$ & 1.4 & $1(0.1)$ & 7.0 \\
\hline Patient 6 & $53(7.0)$ & $53(7.0)$ & 0.0 & $0(0.0)$ & 5.4 \\
\hline Patient 7 & $37(5.5)$ & $39(5.7)$ & -3.5 & $-2(-0.2)$ & 5.7 \\
\hline Patient 8 & $41(5.9)$ & $41(5.9)$ & 0.0 & $0(0.0)$ & 7.1 \\
\hline Patient 9 & $40(5.8)$ & $42(6.0)$ & -3.3 & $-2(-0.2)$ & 7.1 \\
\hline Patient 10 & $62(7.8)$ & $61(7.7)$ & 1.3 & $1(0.1)$ & 7.0 \\
\hline Mean biases & & & +0.9 & $+1.1(+0.1)$ & \\
\hline
\end{tabular}

*Determined using Variant II. ${ }^{\dagger}$ Determined using DCA Vantage.

In this study, we have evidenced that although migrating under the same peak; both $\mathrm{LA}_{1 \mathrm{c}}$ and $\mathrm{cHb}$ interfered differentially with $\mathrm{HbA}_{1 \mathrm{c}}$ measurements. Indeed, the degree of interference greatly varied depending on the nature of the interfering $\mathrm{Hb}$ fractions found under the so-called "LA $1 c$ peak". In the case of the present method, manufacturer recommendations indicated the absence of interference of the peak recognized as $L_{1 c}$ fewer than $3 \%$. Our study evidenced that a significant interference was noticed when $L_{1 c}$ exceeded $4 \%$ and found a significant interfering effect when $\mathrm{CHb}$ exceeded $2 \%$. This interference caused by $\mathrm{cHb}$ could lead to underestimate the value of $\mathrm{HbA}_{1 \mathrm{c}}$ and have an impact on clinical classifications based on $\mathrm{HbA}_{1 \mathrm{c}}$ thresholds, or even on patient management (15).

Thus, we have decided to apply different thresholds depending on the nature of the interference, according to decision tree shown in Figure 3. For differentiating the origin of the interference, we consider (i) the retention time, (ii) the shape of the peak, and (iii) other biological results, especially uraemia. If the peak recognized as " $L A_{1 c}$ " is mainly formed by $L A_{1 c}$, we consider that there is no interference until $4 \%$ of $L A_{1 c}$. When $L A_{1 c}$ is increased 


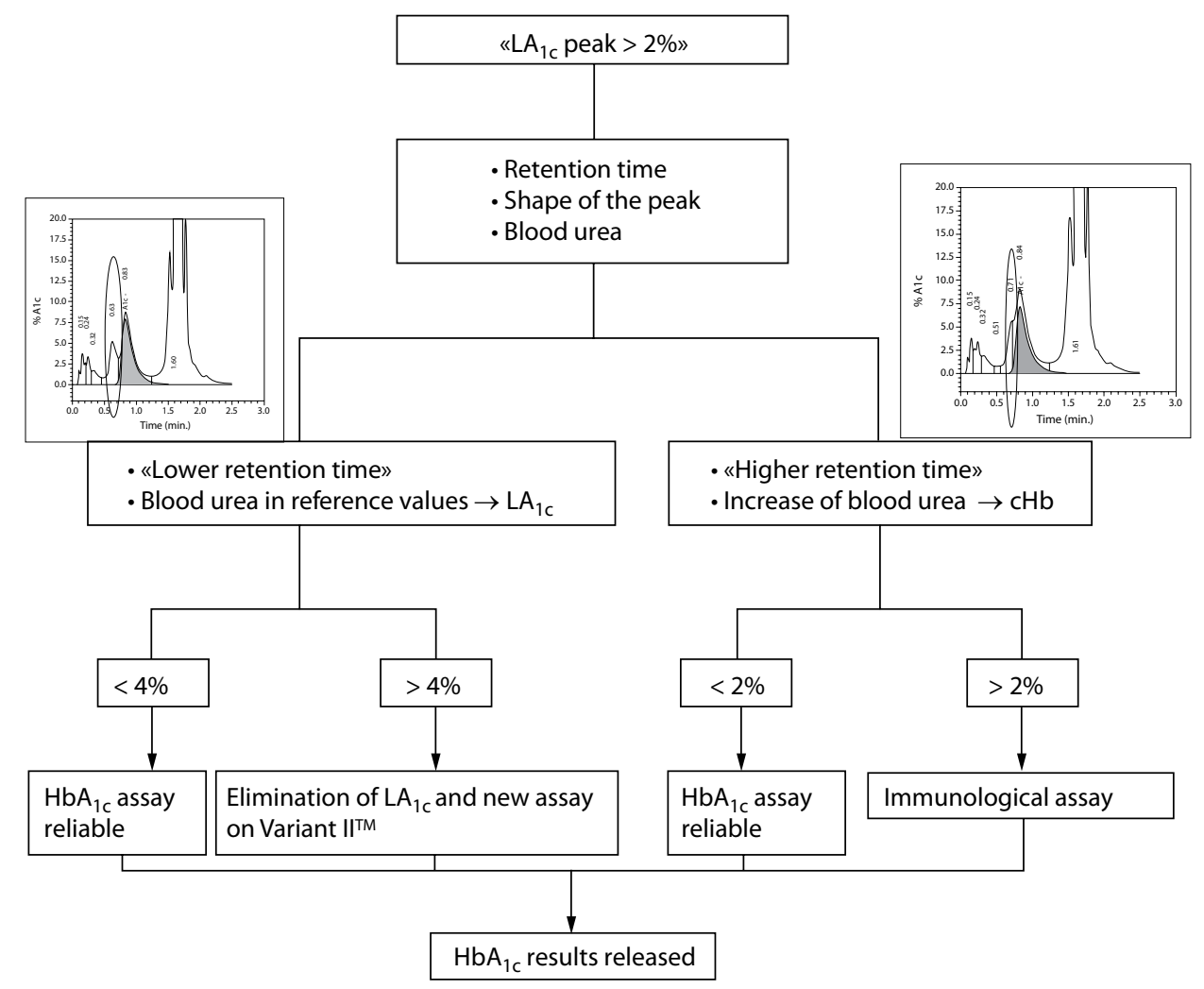

Figure 3. Decision tree in case of " $L A_{1 c}$ peak" higher than $2 \%$

over $4 \%$, this fraction is eliminated by incubation of red blood cells for 30 minutes at $37{ }^{\circ} \mathrm{C}$, according to a previously described procedure (16). If the peak is mainly formed by $\mathrm{cHb}$, we consider a lower interference threshold of $2 \%$. When $\mathrm{cHb}$ values are higher than $2 \%$, as $\mathrm{CHb}$ cannot be eliminated, we do not release values obtained by the HPLC method and perform $\mathrm{HbA}_{1 \mathrm{c}}$ assay using an immunological method, such as on DCA Vantage ${ }^{\circledR}$ System, not influenced by $\mathrm{cHb}$.

\section{References}

1. Gillery P. A history of $\mathrm{HbA1c}$ through clinical chemistry and laboratory medicine. Clin Chem Lab Med 2013;51:65-74. https://doi.org/10.1515/cclm-2012-0548

2. Sacks DB, Arnold M, Bakris GL, Bruns DE, Horvath AR, Kirkman MS, et al. Guidelines and recommendations for laboratory analysis in the diagnosis and management of diabetes mellitus. Clin Chem 2011;57:1-47. https://doi. org/10.1373/clinchem.2010.161596

\section{Conclusion}

This article reminds that $\mathrm{cHb}$ remains a critical issue in chromatography-based $\mathrm{HbA}_{1 c}$ assays. The experimental verifications performed upon implementation of the method in our laboratory led us to change our practice, considering the coelution in a single peak of $\mathrm{LA}_{1 \mathrm{c}}$ and $\mathrm{cHb}$. For that reason, the use of different thresholds ( $2 \%$ or $4 \%$ of $\mathrm{LA}_{1 \mathrm{c}}$ peak) has been established in our daily practice.

\section{Potential conflict of interest}

None declared.

3. Ribeiro RT, Macedo MP, Raposo JF. HbA1c, fructosamine, and glycated albumin in the detection of dysglycaemic conditions. Curr Diabetes Rev 2016;12:14-9. https://doi.org/10. 2174/1573399811666150701143112

4. The Diabetes Control and Complications Trial Research Group. The effect of intensive treatment of diabetes on the development and progression of long-term 
complications in insulin-dependent diabetes mellitus. $N$ Engl J Med 1993;329:977-86. https://doi.org/10.1056/ NEJM199309303291401

5. Armstrong AC, Ambale-Venkatesh B, Turkbey E, Donekal S, Chamera E, Backlund J-Y, et al. Association of cardiovascular risk factors and myocardial fibrosis with early cardiac dysfunction in type 1 diabetes: The diabetes control and complications trial/Epidemiology of diabetes interventions and complications study. Diabetes Care 2017;40:405-11. https://doi.org/10.2337/dc16-1889

6. Jaisson S, Leroy N, Meurice J, Guillard E, Gillery P. First evaluation of Capillarys 2 Flex Piercing ${ }^{\circledast}$ (Sebia) as a new analyzer for HbA1c assay by capillary electrophoresis. Clin Chem Lab Med 2012;50:1769-75. https://doi.org/10.1515/cclm-20120017

7. Szymezak J, Lavalard E, Martin M, Leroy N, Gillery P. Carbamylated hemoglobin remains a critical issue in $\mathrm{HbA1C}$ measurements. Clin Chem Lab Med 2009;47:612-3. https:// doi.org/10.1515/CCLM.2009.136

8. Dolscheid-Pommerich RC, Kirchner S, Weigel C, Eichhorn L, Conrad R, Stoffel-Wagner B, et al. Impact of carbamylation on three different methods, HPLC, capillary electrophoresis and TINIA of measuring HbA1c levels in patients with kidney disease. Diabetes Res Clin Pract 2015;108:15-22. https://doi. org/10.1016/j.diabres.2015.01.034

9. Wu X, Chao Y, Wan Z, Wang Y, Ma Y, Ke P, et al. A comparative evaluation of the analytical performances of Capillarys 2 Flex Piercing, Tosoh HLC-723 G8, Premier Hb9210, and Roche Cobas $\mathrm{c} 501$ Tina-quant Gen 2 analyzers for HbA1c determination. Biochem Med (Zagreb) 2016;26:353-64. https:// doi.org/10.11613/BM.2016.039
10. Moridani MY, Verjee Z, Allen LC. Analytical evaluation of hemoglobin $A(1 C)$ dual kit assay on Bio-Rad Variant II: an automated HPLC hemoglobin analyzer for the management of diabetic patients. Clin Biochem 2003;36:317-20. https:// doi.org/10.1016/S0009-9120(03)00013-4

11. Weykamp CW, Miedema K, de Haan T, Doelman CJ. Carbamylated hemoglobin interference in glycohemoglobin assays. Clin Chem 1999;45:438-40.

12. Desmons A, Jaisson S, Pietrement C, Rieu P, Wynckel A, Gillery P. Homocitrulline: a new marker for differentiating acute from chronic renal failure. Clin Chem Lab Med 2016;54:73-9. https://doi.org/10.1515/cclm-2015-0398

13. Little RR, Rohlfing $C L$, Tennill $A L$, Hanson $S E$, Connolly $S$, Higgins $T$, et al. Measurement of $H b A(1 C)$ in patients with chronic renal failure. Clin Chim Acta 2013;418:73-6. https:// doi.org/10.1016/j.cca.2012.12.022

14. Li Q, Ju Y, Jin T, Pang B, Deng J, Du T, et al. Haemoglobin A1C measurement in patients with chronic kidney disease. Clin Biochem 2014;47:481-4. https://doi.org/10.1016/j.clinbiochem.2013.12.005

15. Sandberg S, Fraser CG, Horvath AR, Jansen R, Jones G, Oosterhuis $W$, et al. Defining analytical performance specifications: Consensus Statement from the 1st Strategic Conference of the European Federation of Clinical Chemistry and Laboratory Medicine. Clin Chem Lab Med 2015;53:833-5. https://doi.org/10.1515/cclm-2015-0067

16. Szymezak J, Leroy N, Lavalard E, Gillery P. [Interference of labile glycated hemoglobin on HbA1c assay by a high pressure liquid chromatography method]. Ann Biol Clin (Paris). 2008;66:459-63. (in French) 